\title{
EDUCAÇÃO EM DIREITOS HUMANOS E AS QUESTÕES DE GÊNERO NA ESCOLA
}

\author{
HUMAN RIGHTS EDUCATION AND GENDER ISSUES AT SCHOOL
}

\author{
SANTOS, Ana Paula da Silva ${ }^{1}$ \\ BRITO, Leandro Teófilo de ${ }^{2}$
}

\section{ResUmo}

A questão dos direitos humanos tem se apresentado como uma problemática de difícil compreensão nos dias atuais, assim como o desafio do reconhecimento das diferenças. Mesmo com a construção de documentos nacionais e internacionais centrados na perspectiva dos direitos humanos, ainda convivemos com fortes violações, múltiplas violências, desigualdades sociais e diversas formas de preconceitos e discriminações no cotidiano das relações sociais. Neste sentido, não podemos deixar de pensar nas questões que envolvem as relações de gênero e as desigualdades sofridas por meninas e mulheres, em diversos espaços sociais, sobretudo na escola. O presente ensaio teórico visa apresentar considerações sobre a educação em direitos humanos e as questões de gênero no contexto escolar, utilizando para tanto a perspectiva intercultural. Esta perspectiva nos coloca no âmbito de compreender a educação em direitos humanos como uma mediação para a construção de uma sociedade inclusiva, igualitária e plural onde os sujeitos possam vivenciar experiências que sejam permeadas pelos direitos humanos e, que, se tornem sujeitos de direito.

PaLAVRAS-CHAVE: Interculturalidade; Gênero; Mulher; Escola; Educação em Direitos Humanos.

\section{ABSTRACT}

The issue of human rights has presented itself as a problem that is difficult to understand today, as well as the challenge of recognizing differences. Even with the construction of national and international documents focused on human rights, we still live with strong violations, multiple violence, social inequalities and various forms of prejudice and discrimination in daily social relations. In this sense, we cannot avoid thinking about the issues that involve gender relations and the inequalities suffered by girls and women in various social spaces, especially in school. This theoretical essay aims to present considerations on human rights education and gender issues at school, using the intercultural perspective. This perspective puts us within the scope of understanding human

\footnotetext{
${ }^{1}$ Professora da Universidade Estácio de Sá. Docente nos cursos de Pedagogia e Educação Física. Rio de Janeiro, RJ, Brasil. e-mail: apss.sol@gmail.com

2 Pós-doutorando em Educação pela Universidade do Estado do Rio de Janeiro (UERJ) e docente do Colégio Pedro II. Rio de Janeiro, RJ, Brasil. e-mail: teofilo.leandro@gmail.com
} 
DOI: $10.12957 / \mathrm{e}-m o s a i c o s .2019 .41229$

rights education as a mediation for the construction of an inclusive, egalitarian and plural society where subjects can live experiences that are permeated by human rights and that they become subjects of those rights.

KeYWORDS: Interculturality; Gender; Women; School; Human Rights Education.

\section{INTRODUÇÃO}

O debate sobre direitos humanos, apesar de urgente e necessário nos dias atuais, vem se tornando cada vez mais um grande desafio para o campo educacional, assim como a questão do reconhecimento das diferenças nas práticas e relações educativas.

O presente ensaio teórico tem como objetivo discutir as relações de gênero na escola e as possíveis contribuições da educação em direitos humanos na superação de desigualdades e preconceitos de gênero, no âmbito escolar.

Desde a promulgação da Declaração Universal dos Direitos Humanos, em 1948, que a problemática da defesa e proteção dos direitos humanos vem se tornando fundamental para a construção de uma sociedade mais justa, menos violenta e mais igualitária. Deste modo, em se tratando de justiça, violência e igualdade não é possível deixar de pensar nas questões que envolvem as relações de gênero e as desigualdades sofridas por meninas e mulheres em diversos espaços sociais, como a família, a escola, a igreja entre outras.

O referido documento evidencia em seu preâmbulo, a busca pela dignidade e o valor da pessoa humana, independente do sexo:

Considerando que os povos das Nações Unidas reafirmaram, na carta, sua fé nos direitos humanos fundamentais, na dignidade se no valor da pessoa humana e na igualdade de direitos do homem e da mulher, e que decidiram promover o progresso social e melhores condições de vida em uma liberdade mais ampla. ${ }^{3}$

O artigo $1^{0}$ destaca a igualdade entre todas as pessoas e a busca pela afirmação da fraternidade: "todos os seres humanos nascem livres e iguais em dignidade e Direitos e, dotados que são de razão e consciência, devem comporta-se fraternalmente uns com os outros".

No $2^{\circ}$ artigo, o documento ressalta a igualdade independente das categorias de raça, cor, sexo entre outras: "toda pessoa tem todos os Direitos e liberdades proclamados nesta Declaração, sem distinção alguma de raça, cor, sexo, idioma, religião, opinião pública ou qualquer outra índole, origem nacional ou social, posição econômica, nascimento ou qualquer outra condição".

\footnotetext{
${ }^{3}$ Declaração Universal dos Direitos Humanos, 1948.
} 
A partir daí, vários outros documentos nacionais e internacionais reiteraram e ampliaram as questões postas pela Declaração, instigando ainda mais a sociedade civil pela busca da igualdade entre as pessoas, assim como a luta contra as formas de violência e desigualdades instaladas em diversos setores da sociedade. Dentre esses documentos, podemos destacar como de fundamental importância para a afirmação dos direitos das mulheres, os documentos redigidos a partir das conferências mundiais sobre a mulher realizadas em diferentes partes do mundo.

A I Conferência Mundial Sobre a Mulher, realizada no México em 1975, reconheceu o direito da mulher à integridade física, inclusive a autonomia de decisão sobre o próprio corpo e o direito à maternidade opcional. Mais adiante, na cidade de Copenhague em 1980, realizou-se a II Conferência mundial sobre a mulher, cujo foco das ações pautou-se na avaliação dos progressos ocorridos nos primeiros cinco anos da década da mulher.

Em seguida, foi realizada em 1985 na cidade de Nairóbi a III Conferência Mundial sobre a Mulher, que se dirigiu para a aprovação de estratégias voltadas para o progresso feminino. Posteriormente, destacamos também a IV Conferência mundial sobre a mulher, realizada em 1995 na cidade de Beijing que com o subtítulo "Igualdade, Desenvolvimento e Paz" concentrou suas ações em uma nova agenda de reivindicações: além dos direitos, as mulheres buscavam a efetivação dos compromissos políticos assumidos pelos governos em conferências internacionais através de políticas públicas.

É importante ressaltar a presença, mais recentemente, de algumas iniciativas referentes à consolidação de políticas públicas para as mulheres e o empoderamento de meninas no contexto brasileiro.

A primeira iniciativa refere-se o Plano Nacional de políticas para as mulheres ${ }^{4}$ (PNPM) desenvolvido pelo governo federal em 2013, no mandato da presidente Dilma Rousseff. O processo de construção desse plano, contou com a participação da sociedade civil, movimento de mulheres rurais e urbanas, movimento feminista e organismos estaduais e municipais de políticas para as mulheres. O foco do PNPM esteve nas políticas que orientam as ações do Estado a fim de combater problemas concernentes às desigualdades que inviabilizam a participação social, democrática e igualitária entre homens e mulheres.

A segunda iniciativa, a pesquisa intitulada Por ser menina no Brasil: Crescendo entre Direitos e Violências ${ }^{5}$ realizada em 2013, teve como objetivo compreender a realidade de 1.771 meninas de 6 a 14 anos em todas as cinco regiões do Brasil. As meninas puderam falar sobre educação, saúde, respeito às diferenças e direitos como questões fundamentais para meninas e meninos. De acordo com a pesquisa,

\footnotetext{
${ }^{4}$ Disponível em: http://bibspi.planejamento.gov.br/handle/iditem/157 . Acesso em: 28 de março de 2019.

${ }^{5}$ Disponível em: http://primeirainfancia.org.br/wp-content/uploads/2015/03/1por ser menina resumoexecutivo2014.pdf . Acesso em 28 de março de 2019.
} 
DOI: $10.12957 / \mathrm{e}-\mathrm{mosaicos} .2019 .41229$

meninas ainda continuam tendo um tratamento diferenciado em relação aos meninos no que se refere às tarefas domésticas e a certas brincadeiras que são consideradas "adequadas" para cada gênero. A pesquisa também apontou a grande suscetibilidade das meninas em relação à violência doméstica.

Diante deste quadro, percebemos a existência de um conjunto de normas e políticas públicas voltadas para a promoção e a proteção dos direitos das mulheres e meninas. Porém, como ressalta Candau (2012), apesar de diversos documentos nacionais e internacionais centrarem-se na perspectiva dos direitos humanos, ainda convivemos com fortes violações, múltiplas formas de violência, desigualdade social e diversas formas de preconceitos e discriminações no cotidiano das relações sociais. Ao mesmo tempo, essa autora também ressalta que é possível perceber neste cenário a gradativa afirmação de uma nova sensibilidade social, ética, política e cultural em relação aos direitos humanos.

Nesse contexto, a criação de leis e decretos e a realização de conferências e encontros não representam a garantia da efetivação dos direitos humanos. Se não forem internalizados nas mentalidades individuais e coletivas, de maneira sistemática e consolidada, não construiremos uma cultura dos direitos humanos em nossa sociedade, onde os processos educacionais se tornam fundamentais (CANDAU, 2012).

Desse modo, a educação em direitos humanos, segundo Candau e Sacavino (2010, p. 13) "[...] favorece o reconhecimento de diferentes grupos sociais, étnicos e culturais, assim como as diferentes formas de construir conhecimento, saberes e racionalidades, gerando espaços para que sejam assumidos pela educação tanto no âmbito formal como não-formal e favorecendo o diálogo intercultural".

Assim, consideramos a educação em direitos humanos um terreno fértil para tratarmos sobre as relações de gênero no âmbito escolar, principalmente, dentre outras questões, em relação à proposta de incorporar a questão das diferenças culturais nos processos educativos.

Iniciaremos o texto destacando o conceito de gênero e os processos sociais, culturais e históricos imbricados nesta construção. Em seguida, problematizaremos o papel da escola na construção/manutenção/transformação das diferenças de gênero e, por fim, ressaltamos os pilares da educação em direitos humanos, dentro da perspectiva intercultural, fundamentais para a superação das desigualdades de gênero no ambiente escolar.

\section{O CONCEITO DE GÊNERO}

Segundo a teórica feminista Joan Scott, o termo gênero, como uma categoria de análise histórica, pode ser definido como "[...] o caráter fundamentalmente social das distinções baseadas no sexo" (1995, p.72). A autora, mergulhada em análises pós-estruturalistas, sobretudo, em diálogo com autores como Michel Foucault e Jacques Derrida, fundamentou grande parte da produção teórica brasileira dos 
DOI: $10.12957 / \mathrm{e}-\mathrm{mosaicos} .2019 .41229$

estudos de gênero nos últimos anos. Joan Scott enfatizava o aspecto relacional das definições normativas da feminilidade e da masculinidade, para postular esse caráter fundamentalmente social atribuído ao sexo.

Quando falo de gênero, quero referir-me ao discurso da diferença dos sexos. Ele não se refere apenas às ideias, mas também às instituições, às estruturas, às práticas quotidianas, como também aos rituais e a tudo que constitui as relações sociais. O discurso é um instrumento de ordenação do mundo, e mesmo não sendo anterior à organização social, ele é inseparável desta. Portanto, o gênero é a organização social da diferença sexual. Ele não reflete a realidade biológica primeira, mas ele constrói o sentido dessa realidade. A diferença sexual não é a causa originária da qual a organização social poderia derivar. Ela é antes uma estrutura social movente, que deve ser analisada nos seus diferentes contextos históricos (SCOTT, 1998, p. 2).

No final dos anos de 1970, historiadoras/es julgaram mais potente a utilização do termo gênero para teorizar sobre a questão da diferença sexual do que tratar da mulher, em análises de forma isolada, e, embora os usos sociológicos do termo pudessem incorporar tônicas funcionalistas e até mesmo essencialistas, as historiadoras feministas, a partir de seu uso, buscaram "[...] enfatizar as conotações sociais em contraste com as conotações físicas de sexo" (SCOTT, 2011, p. 86). Desse modo, como apontou a teórica feminista, também seria possível pensar em diferentes sistemas de gênero e sobre suas relações com outras categorias, tais como raça, etnia e classe social, ou seja, um debate que traria ao conceito de gênero interlocuções com variados aspectos da diferença.

Joan Scott argumenta que o uso do termo gênero colocava homens e mulheres em definições recíprocas, embora a palavra muitas vezes estivesse sendo empregada como sinônimo, de forma simplista, de mulheres e feminino (fato que ainda ocorre nos dias de hoje). A utilização da noção de gênero, nesse sentido, buscava apontar a impossibilidade de se estudar homens e mulheres de maneira separada e fragmentada: "[...] não se pode conceber mulheres, exceto se elas forem definidas em relação aos homens, nem homens, exceto quando eles forem diferenciados das mulheres" (SCOTT, 2011, p. 87).

De acordo com esses estudos, comportamentos, atitudes ou traços da personalidade são construídos em uma dada cultura e em um determinado momento histórico, definindo características femininas e masculinas e diferenciando-as umas das outras conforme o papel que desempenham na sociedade. Entender gênero como construto cultural leva a reflexão acerca das representações de homens e mulheres como diversas e plurais, não apenas entre as sociedades ou momentos históricos, mas no interior de uma dada sociedade. 
DOI: $10.12957 / \mathrm{e}-\mathrm{mosaicos} .2019 .41229$

Assim, argumentos de que a desigualdade entre homens e mulheres é baseada nas diferenças biológicas devem ser contestadas, pois essas diferenças são sempre construídas culturalmente, elas não são dadas ou acabadas num determinado momento, elas são instáveis e, portanto, passíveis de transformação historicamente. Os gêneros se fazem e se refazem continuamente ao longo da existência, que são socialmente produzidos e dependentes da história e das circunstâncias (LOURO, 2000; 2003).

Esse processo de construção de gênero se desenvolve no decorrer da vida através das mais diversas instâncias: família, escola, igreja, entre outros, de cujas práticas sociais nos transformamos em homens ou mulheres. Certas noções percebidas no ambiente escolar que indicam que as meninas devem ser frágeis e estudiosas e que, provavelmente, os meninos serão brutos e bagunceiros estão muito arraigadas na nossa cultura e, com isso, lidamos com elas constantemente em nossas escolas. Essas noções acabam por se naturalizarem de tal modo que se tornam quase imperceptíveis e são construídas sem que os sujeitos se deem conta desse processo.

Segundo Louro (2011), as consequências políticas de noções desse tipo são muito importantes para que possam ser esquecidas porque nelas estão implicadas relações de poder. De acordo com esta autora, há uma profunda desigualdade dividindo homens e mulheres por conta de suas diferenças, pois "os significados atribuídos aos gêneros e às sexualidades são atravessados ou marcados por relações de poder e usualmente implicam em hierarquias, subordinações, distinções" (LOURO, 2011, p. 64). Essa desigualdade estende-se, evidentemente, à educação escolar.

\section{A ESCOLA E DESIGUALDADES DE GÊNERO}

Diversos modos de lidar com o masculino e o feminino foram construídos por diferentes grupos sociais ao longo do tempo. A maneira de se comportar, as formas de vestimentas, a linguagem utilizada, o tempo para o lazer. Essas concepções foram e são aprendidas e interiorizadas de forma naturalizada através de muitas instituições e práticas. A escola é parte fundamental nesse processo. Segundo Louro (2003, p. 57):

Desde seu início, a instituição escolar exerceu uma ação distintiva. Ela se sucumbiu de separar os sujeitos - tornando aqueles que nela entravam distintos dos outros, os que a ela não tinham acesso. Ela dividiu também, internamente, os que lá estavam, através de múltiplos mecanismos de classificação, ordenamento, hierarquização. A escola que nos foi legada pela sociedade ocidental moderna começou por separar adultos de crianças, católicos de protestantes. Ela também se fez diferente para os ricos e para os pobres e ela imediatamente separou meninos de meninas. 
DOI: 10.12957/e-mosaicos.2019.41229

A naturalização, a qual nos referimos, parece estar tão fortemente construída a ponto de nos impedir de notar que, no interior das escolas, meninos e meninas se movimentem, circulem e se agrupem de forma distinta. Tais fatos indicam certa "ordem natural das coisas", porém um longo processo de aprendizado vai determinar o "lugar de cada um". Louro (2003) afirma que dispositivos e práticas da cultura escolar que permeiam o processo ensino-aprendizado e penetram nos sujeitos acabam por constituírem suas identidades escolarizadas. Nesse sentido, "[...] gestos, movimentos, sentidos são produzidos no espaço escolar e incorporados por meninos e meninas, tornando-se partes de seus corpos" (LOURO, 2003, p. 61).

Em se tratando de práticas pedagógicas não podemos deixar de mencionar 0 papel do currículo na transmissão de conhecimentos, valores, normas e padrões. Louro (2000), ao analisar o currículo e as questões de gênero, afirma que é travada no cotidiano escolar uma disputa política em torno das identidades sexuais e de gênero. De um lado a norma branca, masculina, heterossexual e cristã representa o discurso hegemônico; de outro lado, discursos plurais de grupos socialmente excluídos lutam por se fazer ouvir, rompendo o silenciamento ao qual foram historicamente submetidos. Segundo a autora, as práticas escolares e o currículo são instâncias que carregam e produzem representações que vão legitimar os processos de exclusão e inclusão, de valorização ou negação das identidades.

Nesse sentido, Silva (2010) afirma que há uma profunda desigualdade dividindo homens e mulheres, com os primeiros se apropriando de maiores recursos materiais e simbólicos na sociedade. Tal fato, segundo o autor, estende-se à educação e especialmente ao currículo, pois: "Na medida em que reflete a epistemologia dominante, o currículo existente é também claramente masculino" (p.94).

Desse modo, educadores/as comprometidos/as com a justiça e igualdade das relações, devem refletir sobre certas práticas educativas distintas segundo um padrão de ser feminino e ser masculino e promover práticas corporais acessíveis a ambos os gêneros, acompanhado de uma intensa discussão no sentido de combater o sexismo e reconhecer que as diferenças biológicas não são suficientes para determinar a dominação de um sexo sobre o outro.

É fundamental destacar que as distinções presentes na escola em relação às construções das filas para a entrada e saída das salas de aula, o modo de sentar e andar, a linguagem, o currículo, os conteúdos escolares operam na lógica de uma norma hegemônica masculina, branca, heterossexual e cristã, dessa maneira, determinam visões baseadas nas diferenças entre os gêneros, onde qualquer um que se afaste da norma seja considerado um "sujeito diferente" (LOURO, 2011).

Nesse caso, quem é conhecido como sujeito normal? E quem se diferencia desse sujeito? A diferença se constitui em uma relação, atribuída a um sujeito quando o relacionamos a outro que é tomado como norma ou referência. A norma se expressa por meio de recomendações repetidas e observadas cotidianamente que se apresentam como um padrão a ser seguido. Dessa forma, a norma se faz penetrante e capaz de se naturalizar (LOURO, 2008), de modo que as marcas da escolarização 
DOI: $10.12957 / \mathrm{e}-\mathrm{mosaicos} .2019 .41229$

se inscrevem nos corpos dos sujeitos, através de múltiplos e discretos mecanismos separando meninos de meninas, homens de mulheres.

Portanto, se assumimos que a escola não apenas transmite conhecimentos, mas que ela também "fabrica" sujeitos e produz identidades de gênero, se reconhecemos que essas identidades estão sendo produzidas através de relações desiguais de poder, se admitirmos que a prática escolar é historicamente provisória e política, ou seja, pode ser transformada e subvertida e, enfim, se não nos sentimos conformados/as com essas divisões e desigualdades, encontramos, de certa forma, justificativas suficientes para não só perceber, mas atuar no sentido de interferir na continuação dessas desigualdades (LOURO, 2003).

Assim, a educação em direitos humanos proposta neste estudo, caminha no sentido de propor, dentre outras coisas, a desnaturalização de estereótipos e preconceitos, o favorecimento de processos de empoderamento a grupos subalternizados, a construção de sujeitos autônomos e conscientes de seus direitos e o desenvolvimento de situações de aprendizagens capazes de afetar mentalidades, ideias, atitudes e comportamentos (CANDAU; SACAVINO, 2010; CANDAU, 2008).

\section{A EDUCAÇÃO EM DIREITOS HUMANOS: UM CAMINHO POSSÍVEL PARA A SUPERAÇÃO DAS DESIGUALDADES DE GÊNERO?}

O surgimento da educação em direitos humanos, segundo Sacavino (2012), se dá na América Latina, por volta da década de 80 depois das duras experiências com a ditadura militar em diversos países, sendo considerada fundamental para a construção da democracia. No entanto, a educação em direitos humanos apresenta no imaginário social a sua identificação com a "defesa de bandidos" e, em outros casos, o lado do sofrimento humano ocasionado pelas grandes violações à dignidade humana. A autora citada, porém, considera a educação em direitos humanos uma peça primordial para a construção de sociedades felizes.

Para Candau e Sacavino (2010), a educação em direitos humanos veio se afirmar com mais força no Brasil, a partir da primeira década dos anos 2000, tanto na esfera das políticas públicas quanto nas organizações da sociedade civil. Esta gradativa consolidação aconteceu no cenário da educação através de seminários, cursos, palestras organizadas não só por universidades, mas também por associações, movimentos e ONGs. As referidas autoras destacam que dentre todas as iniciativas propostas em âmbito nacional, a implementação do Plano Nacional de Educação em Direitos Humanos representa um papel fundamental para o estímulo e a viabilidade da educação em direitos humanos na escola.

No caso particular deste estudo, destacamos no PNEDH, dentre os seus princípios norteadores na educação básica, um que consideramos fundamental para a reflexão sobre as contribuições da educação em direitos humanos para a superação das desigualdades de gênero na escola: 
A educação em direitos humanos deve estruturar-se na diversidade cultural e ambiental, garantindo a cidadania, o acesso ao ensino, permanência e conclusão, a equidade (étnico-racial, religiosa, cultural, territorial, físico-individual, geracional, de gênero, de orientação sexual, de opção política, de nacionalidade, dentre outras) e a qualidade da educação (PNEDH, 2009, p. 32).

Nesse sentido, percebemos que esse importante documento evidencia a relevância da questão do reconhecimento da diversidade cultural e da equidade entre os sujeitos, independentemente de suas diferenças.

A questão de gênero aparece, entre outras categorias, na busca pela equidade entre meninos e meninas no espaço escolar, ou seja, a busca pela igualdade de direitos de cada um, independente do gênero. A partir daí, podemos compreender a educação em direitos humanos como uma mediação para a construção de uma sociedade inclusiva, igualitária e plural onde os sujeitos vivenciem experiências que sejam permeadas pelos direitos humanos.

Contudo, como destacam Candau e Sacavino (2010), a educação em direitos humanos apresenta um caráter polissêmico que marca fortemente o seu discurso. Em tal estudo, as autoras apontam dois enfoques que consideram mais presentes nas produções teóricas e nas práticas desenvolvidas no campo da educação em direitos humanos.

Inicialmente, consideram a preocupação dos direitos humanos como uma estratégia para melhorar a sociedade dentro do modelo vigente, sem questionamentos. Valorizam as questões éticas e os direitos civis e políticos, relacionando-os na participação das eleições. Na escola, os autores propõem a incorporação no currículo de temas relacionados aos direitos humanos, em uma perspectiva folclórica, de comemoração de datas representativas, sem contextualização e problematização com a realidade.

O segundo enfoque diz respeito aos direitos humanos como um projeto de construção de uma sociedade igualitária, inclusiva, com ênfase em uma cidadania coletiva, que favorece a organização da sociedade civil e dos atores da escola em função da transformação social, que promove processos de empoderamento dos grupos sociais e culturais marginalizados. Do ponto de vista pedagógico, valoriza a existência de possibilidades metodológicas plurais, privilegiando a interdisciplinaridade e priorizando a estratégia de temas geradores voltados para a desestabilização do caráter monocultural do currículo.

As autoras citadas chamam a atenção para o fato de que, em muitos casos, esses dois enfoques se combinam, no entanto, afirmam que é fundamental identificar a principal matriz em cada perspectiva e, sobretudo, fazer opções bem definidas sobre o caminho a percorrer. 
Diante do exposto, esse ensaio compartilha com as ideias do segundo enfoque, concebendo a educação em direitos humanos como um espaço de problematização, questionamento e subversão de desigualdades e também um momento de formação de sujeitos conscientes de seus direitos, no nosso caso particular, a superação das desigualdades de gênero no espaço escolar e a formação de meninas e mulheres conscientes de seus direitos e das lutas pelas quais vem passando no decorrer da história em busca da afirmação da dignidade humana.

Outros estudos também concebem a educação em direitos humanos como um horizonte na construção de uma cidadania plena e participativa.

Para Candau e Sacavino (2009) vem surgindo com força a necessidade de se incorporar a questão das diferenças culturais nos processos educativos. No entanto, consideram que a cultura dominante na escola é marcadamente homogeneizante e monocultural. Segundo as mesmas:

A educação em/para os direitos humanos favorece o reconhecimento de diferentes grupos sociais, étnicos e culturais, assim como de diferentes formas de produzir conhecimentos, saberes e racionalidades, gerando espaços para que sejam assumidos pela educação tanto no âmbito formal como não-formal e favorecendo o diálogo intercultural (CANDAU; SACAVINO, 2009, p. 13).

Candau (2012) defende que a tensão entre igualdade e diferença está presente no desenvolvimento do direito à educação, quanto nos processos de educação em direitos humanos. Estes dois componentes se entrelaçam, segundo esta autora, constituindo uma teia em que a educação em direitos humanos se torna um elemento fundamental do direito à educação. Este processo que considera a articulação entre os direitos da igualdade e os direitos da diferença é, segundo as autoras, uma exigência do momento atual e seu desenvolvimento se dá "[...] formando sujeitos de direito a partir do reconhecimento de suas especificidades de gênero, raça, etnia, territorialidade, etapa de vida, orientação sexual, opção religiosa, características sensório-motoras, aspectos psicológicos, de classe social, entre outras" (CANDAU, 2012, p. 725).

O processo de construção e de implementação da educação em direitos humanos apresenta alguns desafios a serem superados no âmbito educacional.

Como enfatizado anteriormente, a escola opera, em sua maior parte, dentro de uma lógica monocultural e homogeneizante, desde os conteúdos de ensino, passando pelo currículo até a avaliação. Dessa forma, pouco se valoriza e reconhece as diferenças culturais de diferentes grupos de forma crítica e contextualizada, se restringindo apenas a comemorações festivas em dias específicos. 
Nesse sentido, alguns desses desafios são apontados por Candau (2008) no campo da educação em direitos humanos tendo como base a educação intercultural na perspectiva crítica e emancipatória que respeite os direitos humanos e articule questões relativas à igualdade e à diferença. A autora citada, com base em Boaventura de Souza Santos, apresenta esses desafios agrupados em determinados núcleos.

O primeiro está relacionado à necessidade de desconstrução. Para ela, a promoção de uma educação intercultural implica em uma desnaturalização e explicitação de redes de estereótipos e preconceitos que povoam o imaginário individual e coletivo em relação a diferentes grupos socioculturais. No caso do nosso estudo, desestabilizar noções simplistas e excludentes sobre os gêneros torna-se fundamental para a construção de relações de respeito e equidade entre meninos e meninas.

Um segundo núcleo de preocupações, de acordo com a referida autora, é a articulação entre a igualdade e diferença no nível das políticas educativas e nas práticas pedagógicas. Esta preocupação se relaciona com o reconhecimento e valorização das diversas culturas e a afirmação do direito à educação de todos/as. Propiciar experiências pedagógicas múltiplas e de forma igualitária a meninos e meninas no espaço escolar torna-se imprescindível na implantação de uma cultura dos direitos humanos.

Outro núcleo importante é o resgate dos processos de construção das identidades culturais através do resgate das histórias de vida. É importante que estas histórias sejam valorizadas no espaço escolar como parte do processo ensinoaprendizagem com o intuito de se promover o reconhecimento e o diálogo entre os diferentes grupos culturais.

$\mathrm{E}$, por último, promover experiências de interação sistemáticas com os 'outros'. Candau (2008) ressalta que não basta desenvolver momentos pontuais de interação, mas potencializar projetos que suponham uma dinâmica sistemática de diálogo e construção conjunta entre diferentes grupos. Neste caso, propor atividades onde os meninos e as meninas possam interagir de forma conjunta e crítica, desafiando qualquer tipo de preconceito ou discriminação. Neste último núcleo de preocupações, a autora enfatiza também os processos de empoderamento, principalmente aos grupos que, ao longo da história, tiveram menor poder na sociedade. Segundo a autora, este processo se caracteriza por liberar o poder, a potência que cada pessoa tem para ser sujeito de sua própria vida, atuando na transformação social e na correção de marcas de discriminação construídas ao longo da história. 


\section{CONSIDERAÇÕES FINAIS}

Através das considerações pontuadas neste estudo, procuramos evidenciar o quanto as questões de gênero estão intimamente ligadas à defesa e afirmação dos direitos humanos. Quer seja pela construção de políticas de afirmação para as mulheres ou pelo desenvolvimento da educação em direitos humanos no âmbito escolar, a problemática de gênero se coloca como fundamental para construção de sociedades desprovidas de preconceitos e discriminações.

Nesse sentido, a implementação da educação em direitos humanos na escola não se apresenta como uma tarefa fácil, pois exige um trabalho multi e interdisciplinar que permita a construção de uma cultura de direitos humanos, ou seja, que todas as práticas, metodologias e estratégias pedagógicas sejam permeadas pelos direitos humanos e tenham como foco a formação de sujeitos de direitos.

Defendemos, desse modo, a perspectiva da educação em direitos humanos que caminha em direção de uma sociedade justa e igualitária, focalizando uma cidadania coletiva que promove a organização dos atores da escola e da sociedade de maneira geral, segundo a ótica da transformação social, promovendo processos de empoderamento dos grupos sociais, especialmente, os marginalizados historicamente.

É urgente, a nosso ver, a necessidade de, nos dias atuais, conceber a educação em direitos humanos como um espaço de contestação e problematização das desigualdades e, fundamentalmente, um espaço de formação de sujeitos conscientes de seus direitos e participantes de uma sociedade que tenha como mote a luta pela afirmação constante da dignidade humana.

Nesse sentido, a educação em direitos humanos inspirada na educação intercultural crítica enfatiza a articulação das questões relativas à igualdade e à diferença. Para tanto, esta perspectiva procura desestabilizar estereótipos e preconceitos que se expressam no imaginário individual e coletivo da sociedade em relação a diferentes grupos, como no nosso caso, às mulheres. Oportuniza experiências pedagógicas múltiplas onde todos e todas possam vivenciar a equidade e justiça nas relações estabelecidas no espaço escolar, e, por fim, a valorização das histórias de vida, a ênfase nos processos de empoderamento e o reconhecimento do diálogo intercultural.

Sem a pretensão de finalizar o assunto, é fundamental destacar que a educação em direitos humanos na perspectiva intercultural crítica ainda se apresenta em construção, posto que, mesmo diante de um cenário conservador, autoritário e impactado por múltiplas formas de violência contra a mulher, já vislumbramos pistas de sua presença no espaço escolar. 
DOI: $10.12957 /$ e-mosaicos.2019.41229

\section{REFERÊNCIAS}

CANDAU, V. M. F. Direito à educação, diversidade e educação em direitos humanos. Educação e Sociedade. Campinas, v. 33, n. 120, jul-set 2012, p. 715-726.

CANDAU, V. Direitos Humanos, Educação e Interculturalidade: a tensão entre igualdade e diferença. Revista Brasileira de Educação. ANPED, v. 13, n.37, 2008, p. 45-56.

CANDAU, V. M.; SACAVINO, S. Educação em Direitos Humanos: concepções e metodologias. In: FERREIRA, L. de F., ZENAIDE, M. de N.; DIAS, A. (Org.). Direitos Humanos na Educação Superior: subsídios para a Educação em Direitos Humanos na Pedagogia. João Pessoa: Editora Universitária da UFPB, 2010, p. 113-138.

CANDAU, V. M.; SACAVINO, S. Educação em Direitos Humanos no Brasil: ideias-força e perspectivas de futuro; In: MAGDENZO, A. Pensamento e ideas-Fuerza de laeducación em Derechos Humanos em Iberoamerica. Santiago: Ed. Sm/UNESCO/OI, 2009, p. 68-83.

LOURO, G. L. Currículo, Gênero e Sexualidade. Portugal: Porto, 2000. . Gênero, Sexualidade e Educação. 5a ed. Petrópolis: Vozes, 2003. . Gênero e sexualidade: pedagogias contemporâneas. Pro-Posições, v. 19, n. 2, mai/ago 2008.

. Educação e docência: diversidade, gênero e sexualidade. Formação Docente. Belo Horizonte, v. 04, n. 04, jan/jul 2011, p. 62-70.

ORGANIZACAO DAS NAÇÕES UNIDAS (ONU). Declaração Universal dos Direitos Humanos. Paris: ONU, 1948.

SACAVINO, S. Educação em Diretos Humanos: pedagogias do sul. Memorial da Resistência: São Paulo, 2012.

SCOTT, J. Gênero: uma categoria útil de análise histórica. Educação e Realidade. Porto Alegre, v.20, n.2, jul/dez 1995, p. 71-99.

. A invisibilidade da experiência. Projeto História. Revista do Programa de Estudos Pós-Graduados de História. São Paulo, v. 16, jan/jun 1998, p. 297-325.

. História das mulheres. In: BURKE, P. (Org.). A escrita da história: novas perspectivas. São Paulo: UNESP, 2011, p. 63-95.

SEDH. Plano Nacional de Educação em Direitos Humanos. CNEDH/SEDH/MEC/M. Justiça/UNESCO, Brasília, 2009. 
DOI: $10.12957 /$ e-mosaicos.2019.41229

SILVA, T. T. Documentos de identidade: uma introdução às teorias do currículo. $3^{a}$ ed. Belo Horizonte: Autêntica, 2010.

Recebido em 13 de março de 2019.

Aceito em 31 de maio de 2019.

(c) (7) (5) A e-Mosaicos - Revista Multidisciplinar de Ensino, Pesquisa, Extensão e Cultura do Instituto de Licença Creative Commons - Atribuição-NãoComercial 4.0 Internacional.

Os direitos autorais de todos os trabalhos publicados na revista pertencem ao(s) seu(s) autor(es) e coautor(es), com o direito de primeira publicação cedido à e-Mosaicos.

Os artigos publicados são de acesso público, de uso gratuito, com atribuição de autoria obrigatória, para aplicações de finalidade educacional e não-comercial, de acordo com o modelo de licenciamento Creative Commons adotado pela revista. 